\title{
OPEN A descriptive analysis of antimicrobial resistance patterns of WHO priority pathogens isolated in children from a tertiary care hospital in India
}

\begin{abstract}
Vijayalaxmi V. Mogasale ${ }^{1}$, Prakash Saldanha ${ }^{1}$, Vidya Pai ${ }^{2}$, P. D. Rekha ${ }^{3} \&$ Vittal Mogasale ${ }^{4 凶}$
The World Health Organization (WHO) has articulated a priority pathogens list (PPL) to provide strategic direction to research and develop new antimicrobials. Antimicrobial resistance (AMR) patterns of WHO PPL in a tertiary health care facility in Southern India were explored to understand the local priority pathogens. Culture reports of laboratory specimens collected between 1st January 2014 and 31st October 2019 from paediatric patients were extracted. The antimicrobial susceptibility patterns for selected antimicrobials on the WHO PPL were analysed and reported. Of 12,256 culture specimens screened, 2335 (19\%) showed culture positivity, of which $1556(66.6 \%)$ were organisms from the WHO-PPL. E. coli was the most common organism isolated (37\%), followed by Staphylococcus aureus (16\%). Total of $72 \%$ of $E$. coli were extended-spectrum beta-lactamases (ESBL) producers, $55 \%$ of Enterobacteriaceae were resistant to 3rd generation cephalosporins due to ESBL, and $53 \%$ of Staph. aureus were Methicillin-resistant. The analysis showed AMR trends and prevalence patterns in the study setting and the WHO-PPL document are not fully comparable. This kind of local priority difference needs to be recognised in local policies and practices.
\end{abstract}

Antimicrobial resistance (AMR) has been recognised as a major threat to global health ${ }^{1}$. According to the World Health Organization (WHO), mutations in microorganisms resulting in AMR, which consequently render medicines ineffective and infections persist in the body, increasing the risk of spread to others ${ }^{1}$. There are many reasons behind the development of AMR, ranging from microbial causes to human aspects such as overuse and over-prescription of antimicrobials, agricultural and commercial application of antimicrobials in the animal sector, and human behavioural factors ${ }^{2}$. Our ability to treat common pathogens becomes challenging because of AMR, resulting in increased duration of illness, costs, number of complications, and deaths. By 2050, an estimated 10 million deaths are projected to occur due to $\mathrm{AMR}^{3}$, while another study projected AMR to cost the global economy US $\$ 100$ trillion, in the same period ${ }^{4}$.

In 2015, the 68th World Health Assembly endorsed the Global Action Plan on AMR to tackle this global challenge ${ }^{5}$. This action plan has five strategic actions, focusing on (1) improving awareness and understanding of AMR; (2) strengthening AMR surveillance; (3) reducing the incidence of infections; (4) optimizing antimicrobial use; and (5) developing the economic case for AMR control. To support the Global Action Plan, WHO has developed a priority pathogens list (PPL), through a consultative process ${ }^{6}$. The prioritization process involved multi-criteria decision analysis (MCDA) which used information from multiple sources, including disease mortality, transmissibility, treatability, health care burden, preventability in health care settings, and preventability in community settings, etc. Twelve families of drug-resistant bacteria, posing the greatest threat to human health, were categorized as critical, high, and medium priority organisms, in terms of their resistance to selected antimicrobials (Fig. 1). Although this categorization was intended to prioritize and stimulate research and develop new antimicrobials for specific drug resistance, it also makes a call for the prevention of infection and the rational use of antibiotics in both humans and animals ${ }^{6}$.

${ }^{1}$ Department of Paediatrics, Yenepoya Medical College, Mangalore, India. ${ }^{2}$ Department of Microbiology, Yenepoya Medical College, Mangalore, India. ${ }^{3}$ Yenepoya Research Centre, Yenepoya (Deemed to be) University, Mangalore, India. ${ }^{4}$ Policy and Economic Research Department, International Vaccine Institute, Seoul, South Korea. ${ }^{\square}$ email: vmogasale@ivi.int 


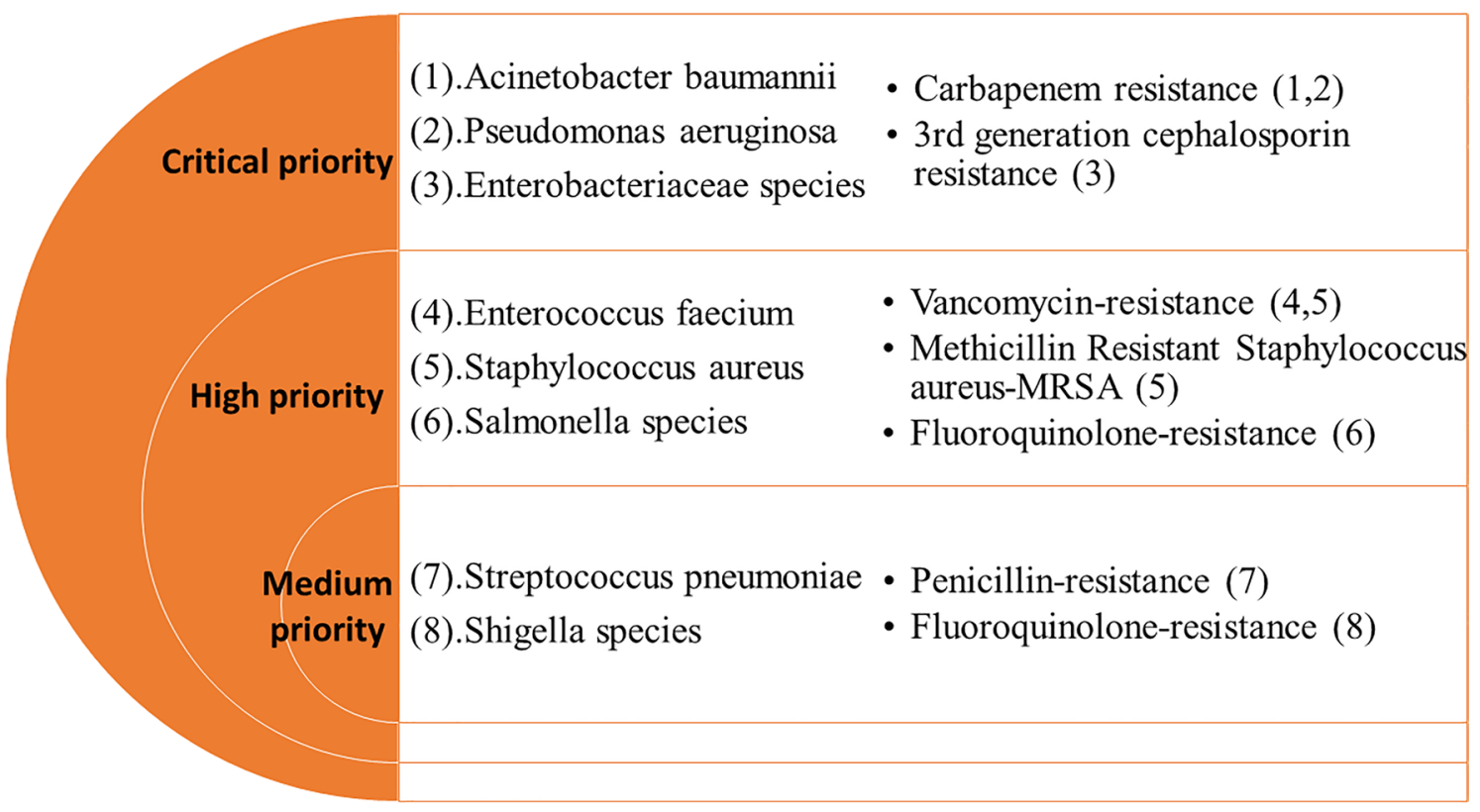

Figure 1. The list of organisms and antimicrobial resistance patterns included in the analysis based on the World Health Organization priority pathogens list (WHO PPL).

Indian population is known to be the highest consumer of antibiotics in the world ${ }^{7}$. The AMR situation in India has raised grave public health concerns ${ }^{8}$ and an action plan for its control is considered crucial ${ }^{9,10}$. Given its importance for human health, the Government of India has developed a National Action Plan on Antimicrobial Resistance (NAP-AMR) 2017-202111. Strengthening the knowledge and evidence base through surveillance of AMR is one of the five key strategies of this action plan. The Indian Council of Medical Research (ICMR) has established an Antimicrobial Resistance Surveillance \& Research Network (AMRSN) across selected hospitals in India, focusing on drug resistance among six pathogens ${ }^{12}$. However, not many hospitals outside this network in India track AMR patterns among these pathogens. Generating AMR related evidence from a larger number of hospitals is critical for informed decision making on AMR related policies and practices at local settings.

This study explores the AMR susceptibility patterns for WHO priority pathogens identified in clinical isolates collected in the Paediatrics Department of a tertiary care hospital in Southern India. The results of the culture tests are mainly availed for treatment purposes but are not systematically analysed on a routine basis. The analysis of culture results could provide further evidence and guidance for the development of antimicrobial resistance control policy at the hospital and elsewhere. This analysis aims to compare AMR patterns in WHO priority pathogens identified in a tertiary health care facility to understand the local priorities that can be applied to local policies and practices.

\section{Results}

A total of 12,256 culture specimens collected at paediatrics outpatient department and paediatrics inpatient wards were screened for bacteriological results, of which 2335 (19\%) showed culture positivity. Of these, 1556 were from the set of WHO PPL organisms. The largest number of bacterial isolation was seen in urine specimens (755/1556) followed by blood (241/1556) (Table 1). E. coli was the most common organism isolated (576), followed by Staphylococcus aureus (252).

Among the main WHO PPL organisms identified, $72 \%$ of E. coli and $63 \%$ of Klebsiella spp. were resistant to 3rd generation cephalosporins due to extended-spectrum beta-lactamase (ESBL), and 53\% of the Staph. aureus were Methicillin-resistant (Table 2). Overall, nearly half of Enterobacteriaceae were resistant to carbapenem (46\%) or 3rd generation cephalosporins due to ESBL (55\%). The carbapenem resistance in Pseudomonas aeruginosa was found low (5\%).

Time trend analysis of selected WHO 'Critical priority' pathogens over the past 4 years showed a high proportion of resistance for carbapenem in E coli, Klebsiella pneumoniae, and Enterobacter cloacae (Fig. 2).

Similarly, E. coli and Klebsiella pneumoniae continued to show a high proportion of ESBL (Fig. 3).

Among the WHO 'High priority' pathogens, Staph. aureus continued to show a high proportion of methicillin-resistance (Fig. 4).

Three of the WHO 'High priority' pathogens namely, Helicobacter pylori (clarithromycin- resistant), Campylobacter spp. (fluoroquinolone-resistant), and Neisseria gonorrhoeae (3rd generation cephalosporin-resistant and fluoroquinolone-resistant), were not detected in our study specimens and antimicrobial sensitivity information was not available. Similarly, one of the WHO 'Medium priority' pathogen, Haemophilus influenzae (ampicillinresistant), was not observed in this study, and antimicrobial sensitivity information was not available. 


\begin{tabular}{|c|c|c|c|c|c|c|c|c|c|c|c|c|c|c|}
\hline Specimen & Blood & Urine & Stool & Pus & Sputum & $\begin{array}{l}\text { CSF and sterile } \\
\text { fluids }\end{array}$ & Aspirate & Swab & Tissue & $\begin{array}{l}\text { Central lines } \\
\text { and stents }\end{array}$ & Catheter tip & ET tip & \begin{tabular}{|l} 
Other \\
instruments
\end{tabular} & Total \\
\hline \multicolumn{15}{|c|}{ Critical priority organisms } \\
\hline $\begin{array}{l}\text { Acinetobacter } \\
\text { baumannii }\end{array}$ & 6 & 17 & 0 & 1 & 3 & 1 & 2 & 4 & 0 & 6 & 11 & 10 & 4 & 65 \\
\hline $\begin{array}{l}\text { Pseudomonas } \\
\text { aeruginosa }\end{array}$ & 5 & 23 & 0 & 7 & 6 & 1 & 3 & 6 & 1 & 31 & 16 & 16 & 2 & 117 \\
\hline \multicolumn{15}{|l|}{ Enterobacteriaceae } \\
\hline E. coli & 13 & 447 & 29 & 28 & 5 & 4 & 2 & 8 & 8 & 4 & 15 & 7 & 6 & 576 \\
\hline Klebsiella spp. & 35 & 124 & 4 & 7 & 11 & 2 & 2 & 7 & 1 & 10 & 13 & 13 & 0 & 229 \\
\hline $\begin{array}{l}\text { Enterobacter } \\
\text { spp. }\end{array}$ & 31 & 53 & 4 & 4 & 3 & 2 & 3 & 5 & 2 & 7 & 38 & 6 & 4 & 162 \\
\hline Serratia spp. & 0 & 17 & 0 & 1 & 1 & 0 & 1 & 0 & 0 & 1 & 5 & 3 & 1 & 30 \\
\hline Proteus spp. & 0 & 21 & 0 & 3 & 0 & 1 & 0 & 1 & 0 & 0 & 0 & 0 & 1 & 27 \\
\hline $\begin{array}{l}\text { Providencia } \\
\text { spp. }\end{array}$ & 0 & 5 & 0 & 0 & 0 & 0 & 0 & 0 & 0 & 0 & 0 & 0 & 0 & 5 \\
\hline Citrobacter spp. & 0 & 16 & 0 & 1 & 2 & 0 & 0 & 1 & 0 & 3 & 12 & 6 & 5 & 46 \\
\hline Morganella spp. & 0 & 8 & 0 & 0 & 0 & 0 & 0 & 0 & 0 & 0 & 0 & 0 & 0 & 8 \\
\hline Others spp. & 0 & 2 & 0 & 0 & 0 & 0 & 0 & 0 & 0 & 1 & 2 & 1 & 0 & 6 \\
\hline \multicolumn{15}{|c|}{ High priority organisms } \\
\hline $\begin{array}{l}\text { Enterococcus } \\
\text { faecium }\end{array}$ & 5 & 9 & 0 & 0 & 0 & 0 & 0 & 0 & 0 & 0 & 1 & 0 & 0 & 15 \\
\hline $\begin{array}{l}\text { Staphylococcus } \\
\text { aureus }\end{array}$ & 135 & 12 & 0 & 66 & 2 & 0 & 1 & 26 & 0 & 2 & 2 & 4 & 2 & 252 \\
\hline $\begin{array}{l}\text { Salmonella } \\
\text { species }\end{array}$ & 8 & 0 & 0 & 0 & 0 & 0 & 0 & 0 & 0 & 0 & 0 & 0 & 0 & 8 \\
\hline \multicolumn{15}{|c|}{ Medium priority organisms } \\
\hline $\begin{array}{l}\text { Streptococcus } \\
\text { pneumoniae }\end{array}$ & 3 & 0 & 0 & 0 & 1 & 0 & 0 & 2 & 0 & 0 & 0 & 0 & 0 & 6 \\
\hline Shigella species & 0 & 1 & 3 & 0 & 0 & 0 & 0 & 0 & 0 & 0 & 0 & 0 & 0 & 4 \\
\hline Total organisms & 241 & 755 & 40 & 118 & 34 & 11 & 14 & 60 & 12 & 65 & 115 & 66 & 25 & 1556 \\
\hline
\end{tabular}

Table 1. World Health Organisation (WHO) Pathogen Priority List (PPL) organisms isolated in the study site by specimen type from January 2014 to October 2019. CSF cerebrospinal fluid, ET endo tracheal.

\section{Discussion}

The 2017 guidance document of WHO indicated the highest carbapenem resistance worldwide in Acinetobacter baumannii (91\%) and Pseudomonas aeruginosa (82\%), which is one of the reasons for classifying them as Critical Priority ${ }^{6}$ pathogens. The same study reported $>50 \%$ carbapenem resistance in Acinetobacter baumannii, and $31 \%$ to $50 \%$ carbapenem resistance in Pseudomonas aeruginosa in the Indian sub-continent in the general population. Early results from the surveillance data from up to 22 ICMR-AMRSN sites in India showed around $80 \%$ carbapenem resistance in Acinetobacter baumannii and around 30\% in Pseudomonas aeruginosa ${ }^{12}$. However, another study in children from Mumbai, India, identified only $15 \%$ of Pseudomonas aeruginosa are resistant to carbapenem ${ }^{13}$ which is comparable to current study. The carbapenem-resistance in Acinetobacter baumannii and Pseudomonas aeruginosa are $12 \%$ and 5\% respectively in the current study in paediatric population.

The WHO report ${ }^{6}$ identified high carbapenem resistance in E. coli (55\%), Klebsiella (70\%), and Enterobacter spp. (59\%) in the general population, which is not far apart to the findings in this study in paediatric population. The ICMR-AMRSN data also showed similar carbapenem resistance prevalence in Klebsiella pneumoniae (40-50\%) but a significantly lower level in E. coli (15-25\%) in the general population ${ }^{12}$. The ESBL trends in $E$. coli and Klebsiella spp. (70-80\%) as well as methicillin-resistance in Staph. aureus (53\%) were high in this study and comparable to the WHO report. However, due to the low sample size of Salmonella spp., Shigella spp. and Streptococcus pneumoniae, it may not be appropriate to compare the results from this study to others.

Several studies on AMR have been published in India in recent years ${ }^{13-15}$. A retrospective 5 year follow-up study in a tertiary care hospital in North India showed increasing trends of AMR in urinary tract infectioncausing isolates ${ }^{14}$. Increasing trends of AMR was observed among gram negative isolates from samples collected across seven hospitals in India over 4 years, but the reported carbapenem resistance prevalence in Klebsiella spp. (39\%) and E. coli (12\%) were lower than current study ${ }^{15}$. Among Enterobacteriaceae isolated from a paediatric tertiary care hospital in Mumbai, 24\% were extended spectrum beta-lactamase (ESBL) producers and 27\% were carbapenem-resistant isolates showing a lower resistance level than the current study ${ }^{13}$.

As our study is based on a retrospective dataset, it has several limitations. Although the health facility maintains a good quality of clinical and laboratory services along with proper documentation, one cannot ensure that the quality checks in retrospective data are fully compatible with the highest quality standards of a wellconducted prospective study. Although the sample collection, microbiological analysis, and report updates use standard procedures, it has likely been conducted by different people over the 5 year period, which may have had inter-personnel variations on the quality of laboratory procedures. It is possible that at any given point of 


\begin{tabular}{|c|c|c|c|c|c|c|c|}
\hline \multirow[b]{2}{*}{$\begin{array}{l}\text { Critical priority } \\
\text { organisms }\end{array}$} & \multirow[b]{2}{*}{ Isolated (n) } & Tested (n) & Resistant (n) & Resistant (\%) & Tested (n) & Resistant (n) & Resistant (\%) \\
\hline & & \multicolumn{3}{|c|}{ Carbapenem-resistant } & \multicolumn{3}{|c|}{$\begin{array}{l}\text { 3rd generation cephalosporin-resistance } \\
\text { due to ESBL }\end{array}$} \\
\hline Enterobacteriaceae & 1089 & 606 & 276 & 45.54 & 721 & 396 & 54.92 \\
\hline E. coli & $576^{\mathrm{a}}$ & 342 & 140 & 40.94 & 410 & 297 & 72.44 \\
\hline Klebsiella spp. & $229^{a}$ & 107 & 58 & 54.21 & 133 & 84 & 63.16 \\
\hline Enterobacter spp. & $162^{\mathrm{a}}$ & 103 & 59 & 57.28 & 111 & 8 & 7.21 \\
\hline Serratia spp. & $30^{\mathrm{a}}$ & 10 & 9 & 90.00 & 10 & 2 & 20.00 \\
\hline Proteus spp. & $27^{\mathrm{a}}$ & 15 & 1 & 6.67 & 20 & 0 & 0.00 \\
\hline Providencia spp. & $5^{\mathrm{a}}$ & 4 & 1 & 25.00 & 5 & 0 & 0.00 \\
\hline Citrobacter spp. & $46^{\mathrm{a}}$ & 13 & 6 & 46.15 & 19 & 4 & 21.05 \\
\hline Morganella spp. & $8^{\mathrm{a}}$ & 6 & 0 & 0.00 & 7 & 1 & 14.29 \\
\hline Others spp. & $6^{\mathrm{a}}$ & 6 & 2 & 33.33 & 6 & 0 & 0.00 \\
\hline $\begin{array}{l}\text { Acinetobacter } \\
\text { baumannii }\end{array}$ & 65 & 52 & 6 & 11.54 & & & \\
\hline \begin{tabular}{|l|}
$\begin{array}{l}\text { Pseudomonas } \\
\text { aeruginosa }\end{array}$ \\
\end{tabular} & 117 & 59 & 3 & 5.08 & & & \\
\hline \multirow[b]{2}{*}{$\begin{array}{l}\text { High priority } \\
\text { organisms }\end{array}$} & & Tested & Resistant & Percentage (\%) & Tested & Resistant & Percentage \\
\hline & & \multicolumn{3}{|c|}{ Vancomycin-resistant } & \multicolumn{3}{|c|}{$\begin{array}{l}\text { Methicillin-resistant Staphylococcus aureus } \\
\text { (MRSA) }\end{array}$} \\
\hline $\begin{array}{l}\text { Staphylococcus } \\
\text { aureus }\end{array}$ & 252 & 174 & 3 & 1.72 & 188 & 99 & 52.66 \\
\hline \multirow[t]{2}{*}{$\begin{array}{l}\text { Enterococcus } \\
\text { faecium }\end{array}$} & 15 & 15 & 2 & 13.33 & & & \\
\hline & & \multicolumn{3}{|c|}{\begin{tabular}{|l} 
Fluoroquinolone-resistant \\
\end{tabular}} & & & \\
\hline Salmonella species & 8 & 4 & 3 & 75.00 & & & \\
\hline \multirow{2}{*}{$\begin{array}{l}\text { Medium priority } \\
\text { organisms }\end{array}$} & & Tested & Resistant & Percentage (\%) & & & \\
\hline & & \multicolumn{3}{|c|}{\begin{tabular}{|l|} 
Fluoroquinolone-resistant \\
\end{tabular}} & & & \\
\hline \multirow[t]{2}{*}{ Shigella species } & 4 & 4 & 3 & 75.00 & & & \\
\hline & & \multicolumn{3}{|c|}{ Penicillin-resistant } & & & \\
\hline $\begin{array}{l}\begin{array}{l}\text { Streptococcus } \\
\text { pneumoniae }\end{array} \\
\end{array}$ & 6 & 6 & 2 & 33.33 & & & \\
\hline Total organisms & 1556 & & & & & & \\
\hline
\end{tabular}

Table 2. Selected antimicrobial resistance in World Health Organisation (WHO) Pathogen Priority List (PPL) organisms isolated in the study from January 2014 to October 2019. ESBL extended-spectrum $\beta$-lactamases. ${ }^{a}$ These numbers are already counted in the subtotal.

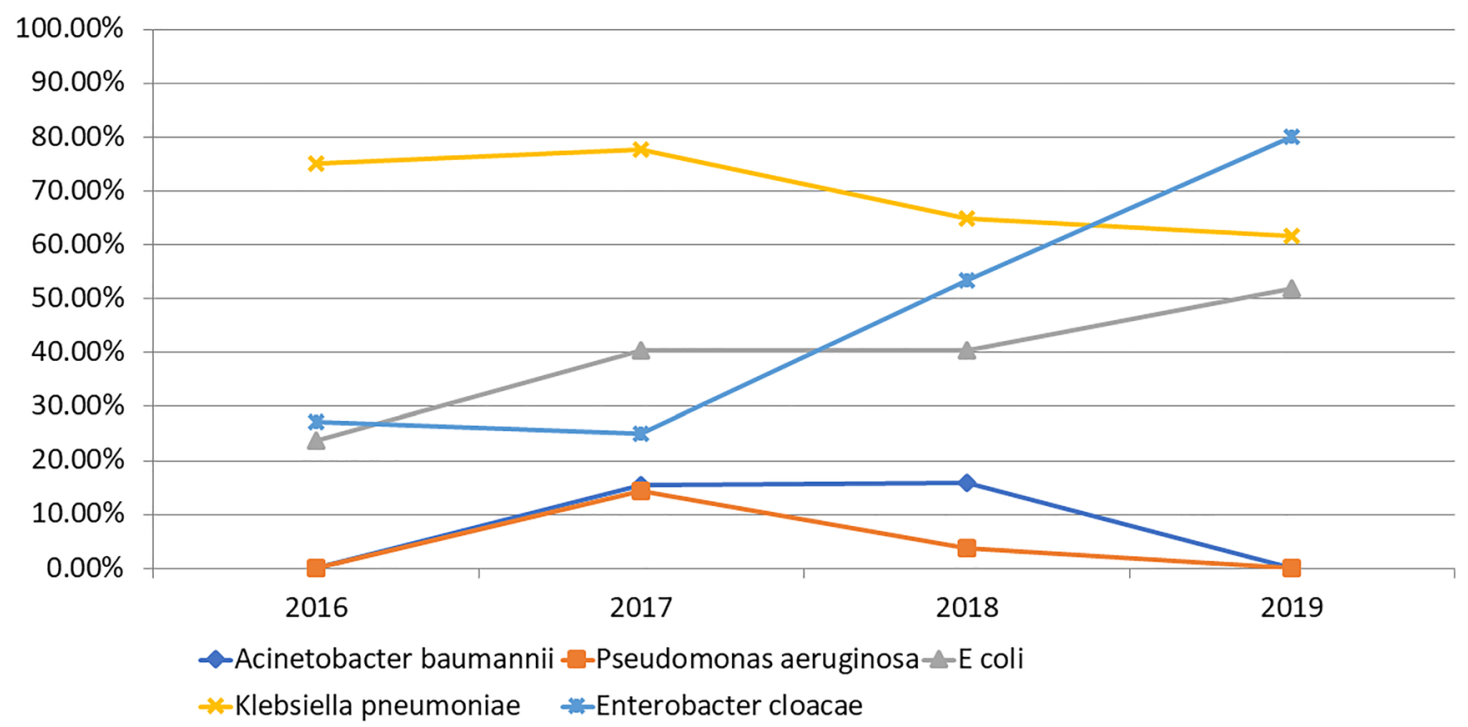

Note: WHO PPL has only two antimicrobials (Carbapenem \& Third generation cephalosporin) listed for critical priority organisms.

Figure 2. Carbapenem-resistance trends among selected WHO Critical Priority Pathogens. 


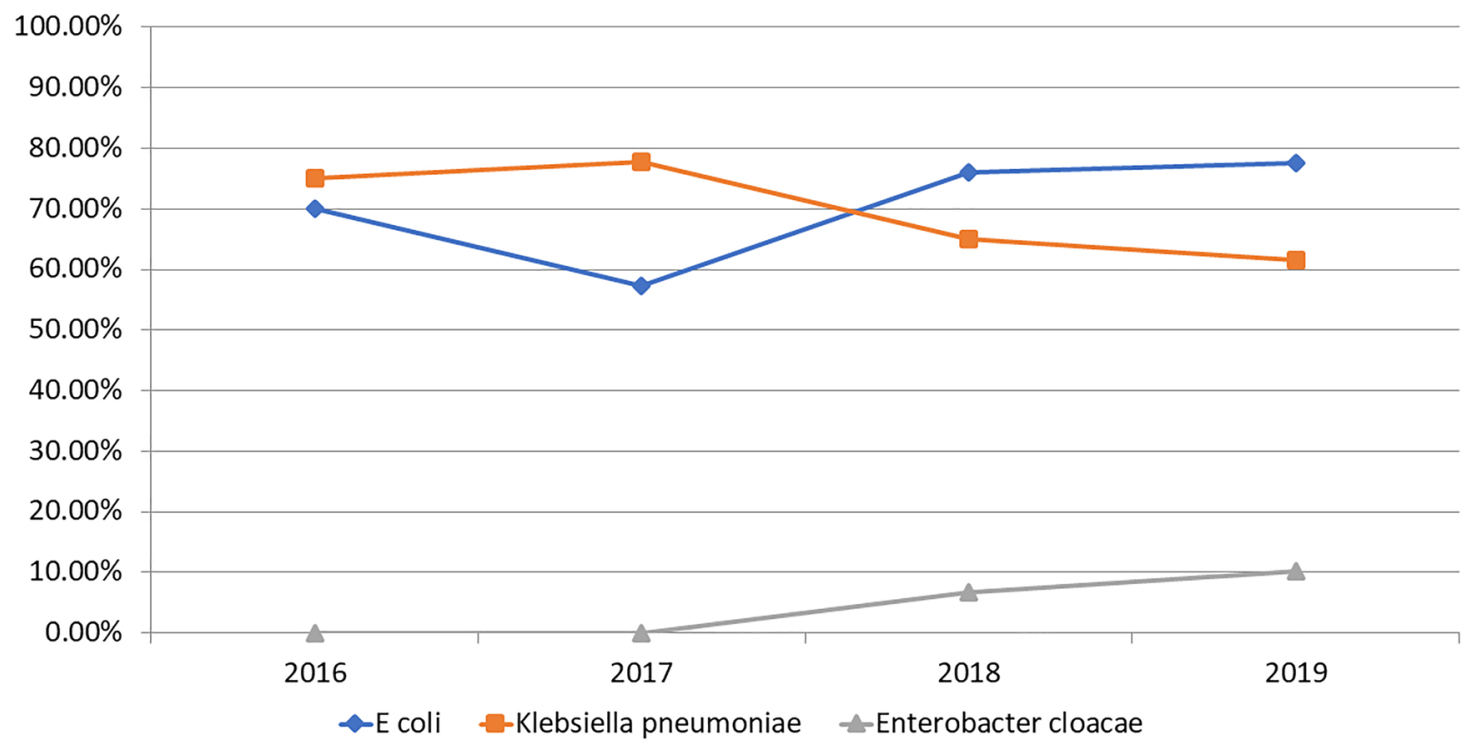

Note: WHO PPL has only two antimicrobials (Carbapenem \& Third generation cephalosporin) listed for critical priority organisms.

Figure 3. Third generation cephalosporin-resistant trends (due to extended-spectrum beta-lactamases (ESBL)) among selected WHO Critical Priority Pathogens.

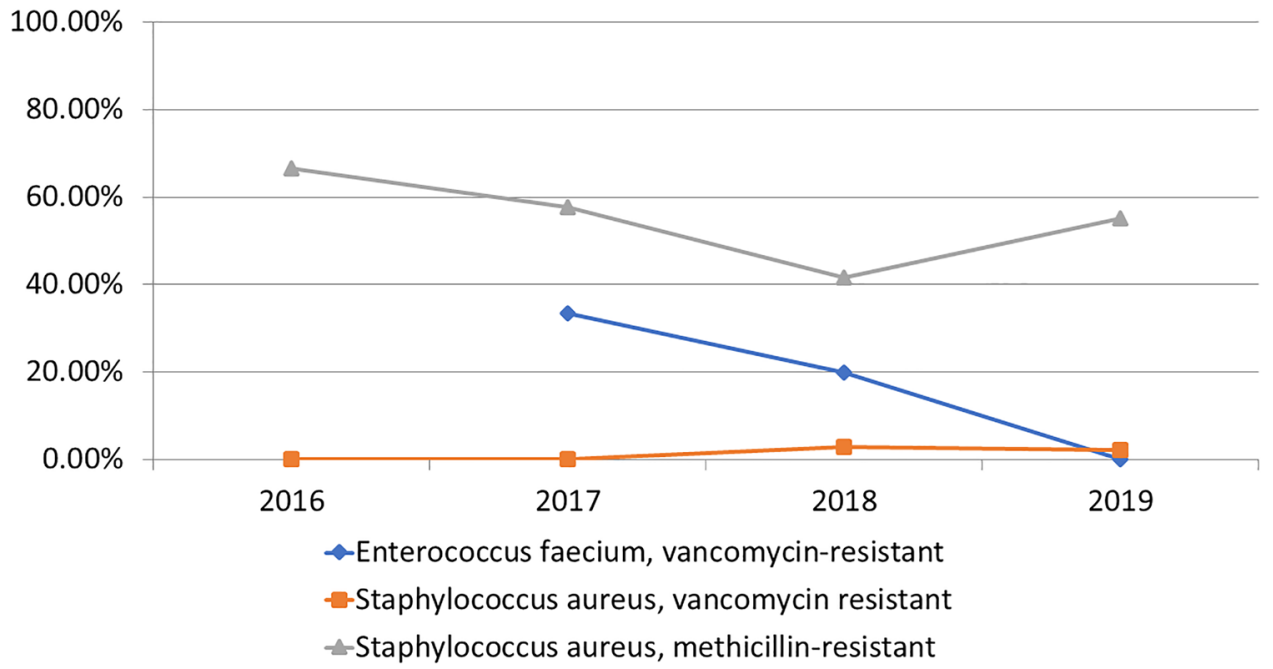

Figure 4. Resistance trends among selected WHO High Priority Pathogens.

the study period new laboratory staff may have joined, may have taken time while undergoing training to implement standardized procedures. Also, laboratory reports are manually entered into computerized system which is subject to human error and specific terms used during data entry are subject to human variations. There were no standard inclusion criteria for sample collection as it was generally left to the discretion of the treating physician.

In conclusion, among the WHO PPL pathogens, E. coli, Klebsiella species, Enterobacteriaceae, and Staph. aureus (methicillin-resistant) have high AMR in the study site. On the other hand, AMR patterns for Acinetobacter baumanni, Pseudomonas aeruginosa, and Staph. aureus (vancomycin resistant) is lower than the WHO global estimates. These findings can guide local priorities, policy, and practices. We recommend large health facilities to monitor and review emerging AMR patterns and trends periodically to prioritise, plan, and implement health facility level policies and guidelines for the optimal use of antimicrobials.

\section{Methods}

The study was conducted at the Yenepoya Medical College Hospital in Mangalore, South India. Typically, the Paediatric Department collected around 2000 clinical specimens every year for culture tests from both outpatient and hospitalized cases. The sources and types of specimens collected for culture included blood, urine, stool, pus, cerebrospinal fluid (CSF), sputum, and any other bodily fluids or other clinical specimens such as catheter, umbilical, and central line tips. As this is a retrospective study, the sample selection for specimen collection 
was left to the discretion of the treating physician as sampling criteria was not predefined. The specimens were referred to the laboratory in the Department of Microbiology for antimicrobial culture tests and antibiogram. The Kirby-Bauer disk diffusion method and/or by BD phoenix automated system were used for performing antimicrobial susceptibility patterns and reported according to standard (Clinical Laboratory Standards Institute-CLSI) guidelines ${ }^{16-20}$. The confirmation of ESBL was done as per the same CLSI guidelines. Once tests were performed, results were entered into the computer backbone system at the Department of Microbiology which was a specific database for the tertiary hospital included in the study. The antibiogram reports generally covered the following antimicrobials: Carbapenem, Chloramphenicol, Cotrimoxazole, Nitrofurantoin, Piperacillin, Piperacillin-Tazobactam, Tetracyclin, Tigecycline, Aztreonam, Amikacin, Gentamycin, Tobramycin, Ciprofloxacin, Levofloxacin, Norfloxacin, Cefoperazone, Ceftriaxone, Cefotaxime, Ceftazidime, Cefepime, Cefazolin, Cefuroxime, Cefoxitin, Imipenem, Meropenem, Polymyxin B, and Colistin. The sample collection, microbiological analysis, and report entry on the computer were done on a routine basis alongside the provision of healthcare services. These test results for antimicrobial susceptibility patterns were retrospectively accessed through the computer backbone system during this study.

Administrative permission to access laboratory culture records was obtained from Yenepoya Medical College. Retrospective culture reports between 1st January 2014 to 31st October 2019 from various clinical specimens were extracted from the computer backbone system. The culture access numbers for all specimens with positive results were used to track the antibiogram (i.e., which antibiotics were tested, and which were susceptible or resistant) results. The antibiogram for all culture isolates was extracted. Culture access numbers were also used to track the culture source and the date of sample collection to the antibiograms.

Culture reports of all paediatric cases were included in the study, irrespective of the location of sample collection, namely: outpatients, inpatient wards, and neonatal and paediatric intensive care units (ICUs). The laboratory reports indicating contamination were excluded at data entry. The reports containing duplicate or repeat samples, from the same source and subject, were also excluded so that the results for the same pathogens are not duplicated or repeated in the analysis. Pathogens other than those in the WHO PPL were excluded from the analysis. The antimicrobial sensitivity tests other than the ones listed in WHO PPL were also excluded from the analysis. Some of the WHO PPL pathogens were not included in this study as culture specimens were collected from children which do not generally include genitourinary swabs or gastric biopsy specimens suitable for the culture of Neisseria gonorrhoeae or Helicobacter pylori. Similarly, Campylobacter spp. was also not identified in the specimens either because of low incidence or because samples collected may not be best suited for its isolation.

The data entry and analysis were performed on Microsoft Excel. The data from the computer backbone was entered directly on a master Excel sheet followed by the removal of duplicates. De-identified data were organised by specimen types (such as blood, urine, etc.) in chronological order of specimen collection date. A list of WHO PPL bacterial pathogens isolated were prepared by their species (such as E coli), specimen type, and resistance patterns. The list classified pathogens into three main groups (Critical Priority, High Priority, and Medium Priority) for selected antimicrobials, based on WHO PPL (Fig. 1). The PPL defines the priority of pathogens based on resistance to specific antimicrobials such as carbapenems, 3rd generation cephalosporins, vancomycin, methicillin, penicillins, or fluoroquinolones. A table presenting the number of organisms isolated in the study site by specimen type was prepared. Another table was prepared to present selected AMR patterns in specific pathogens as defined by WHO PPL. Time trend graphs were prepared for some key pathogens.

Ethical issues. This study did not involve human subjects directly. An approval from the scientific and ethics committees of Yenepoya Medical College (Name: Yenepoya Ethics Committee-1) was obtained for this study. The Yenepoya Ethics Committee-1 waived the need for participants to provide informed consent. To maintain confidentiality, no identifiable information such as names, addresses, or phone numbers of subjects were collected. The data set, once finalised, was delinked from culture access numbers before analysis, to retain confidentiality.

Ethics approval and consent to participate. The Yenepoya Ethics Committee-1 waived the need for participants to provide informed consent as described under the manuscript. This study did not involve human subjects directly, no consent process was involved. All methods were carried out in accordance with relevant guidelines and regulations.

Consent for publication. All authors have consented for publication.

\section{Data availability}

All the data included in the manuscript.

Received: 19 July 2020; Accepted: 9 February 2021

Published online: 04 March 2021

\section{References}

1. WHO. Antimicrobial resistance2018 October 13, 2019. https://www.who.int/news-room/fact-sheets/detail/antimicrobial-resis tance. Accessed 13 Oct 2019.

2. Michael, C. A., Dominey-Howes, D. \& Labbate, M. The antimicrobial resistance crisis: Causes, consequences, and management. Front. Public Health. 2, 145 (2014).

3. Trotter, A. J., Aydin, A., Strinden, M. J. \& O'Grady, J. Recent and emerging technologies for the rapid diagnosis of infection and antimicrobial resistance. Curr. Opin. Microbiol. 51, 39-45 (2019). 
4. O’Neill J. Review on Antimicrobial Resistance. Tackling drug Resistant Infections Globally: Final Report and Recommendations2016 October 13, 2019. https://amr-review.org/sites/default/files/160518_Final\%20paper_with\%20cover.pdf. Accessed 13 Oct 2019.

5. WHO. Global action plan on antimicrobial resistance2015 October 13, 2019. http://www.who.int/antimicrobial-resistance/globa 1-action-plan/en/. Accessed 13 Oct 2019.

6. WHO. Prioritization of pathogens to guide discovery, research and development of new antibiotics for drug resistant bacterial infections, including tuberculosis 2017 October 13, 2019. https://www.who.int/medicines/areas/rational_use/prioritization-ofpathogens/en/. Accessed 13 Oct 2019.

7. Laxminarayan, R. \& Chaudhury, R. R. Antibiotic resistance in india: Drivers and opportunities for action. PLoS Med. 13(3), e1001974 (2016).

8. Ganguly N. Situation Analysis: Antibiotic Use and Resistance in India 2011 October 13, 2019. https://cddep.org/wp-content/uploa ds/2017/06/india-report-web_8.pdf. Accessed 13 Oct 2019.

9. Kumar, S. G. et al. Antimicrobial resistance in India: A review. J. Nat. Sci. Biol. Med. 4(2), 286-291 (2013).

10. Kakkar, M., Walia, K., Vong, S., Chatterjee, P. \& Sharma, A. Antibiotic resistance and its containment in India. BMJ 358, j2687 (2017).

11. National Action Plan on Antimicrobial Resistance (NAP-AMR) 2017-2021. http://www.searo.who.int/india/topics/antimicrob ial_resistance/nap_amr.pdf. Accessed 13 Oct 2019.

12. Walia, K. et al. Establishing antimicrobial resistance surveillance \& research network in india: Journey so far. Indian J. Med. Res. 149(2), 164-179 (2019).

13. Thacker, N. et al. Epidemiology of blood stream infections in pediatric patients at a Tertiary Care Cancer Centre. Indian J. Cancer. 51(4), 438-441 (2014).

14. Patwardhan, V., Kumar, D., Goel, V. \& Singh, S. Changing prevalence and antibiotic drug resistance pattern of pathogens seen in community-acquired pediatric urinary tract infections at a tertiary care hospital of North India. J. Lab. Physicians. 9(4), 264-268 (2017).

15. Veeraraghavan, B. et al. Antimicrobial susceptibility profiles of gram-negative bacteria causing infections collected across India during 2014-2016: Study for monitoring antimicrobial resistance trend report. Indian J. Med. Microbiol. 36(1), 32-36 (2018).

16. CLSI-M100-24-2014. Performance Standards for Antimicrobial Susceptibility Testing (M100). 24th ed. The Clinical Laboratory Standards Institute 2014. https://clsi.org/standards/products/microbiology/documents/m100/. Accessed 12 Dec 2020.

17. CLSI-M100-25-2015. Performance Standards for Antimicrobial Susceptibility Testing (M100). 25th ed. The Clinical Laboratory Standards Institute 2015. https://clsi.org/standards/products/microbiology/documents/m100/. Accessed 12 Dec 2020.

18. CLSI-M100-26-2016. Performance Standards for Antimicrobial Susceptibility Testing (M100). 26th ed. The Clinical Laboratory Standards Institute 2016. https://clsi.org/standards/products/microbiology/documents/m100/. Accessed 12 Dec 2020.

19. CLSI-M100-27-2017. Performance Standards for Antimicrobial Susceptibility Testing (M100). 27th ed. The Clinical Laboratory Standards Institute 2017. https://clsi.org/standards/products/microbiology/documents/m100/. Accessed 12 Dec 2020.

20. CLSI-M100-28-2018. Performance Standards for Antimicrobial Susceptibility Testing (M100). 28th ed. The Clinical Laboratory Standards Institute 2018. https://clsi.org/standards/products/microbiology/documents/. Accessed 9 Mar 2020.

\section{Acknowledgements}

We thank Mr. Satyajit Sarkar for editing and Ms. Athira Ramesh for research support.

\section{Author contributions}

V.V.M. served as Principal Investigator for this study and took overall responsibility for protocol development, study design, ethics approval, data collection, analysis, and drafted the manuscript. V.M. conceptualized the study design, guided data extraction, analysis, and edited the manuscript. P.S., V.S., and R.P.D. provided institutional support in data collection, expert advice, and contributed to the manuscript. All authors have approved the final version of the manuscript.

\section{Funding}

This research was funded by the International Vaccine Institute by the Swedish International Development Cooperation Agency [5410054] and the Bill \& Melinda Gates Foundation. The International Vaccine Institute acknowledges its donors including the Republic of Korea and the Republic of India.

\section{Competing interests}

The authors declare no competing interests.

\section{Additional information}

Correspondence and requests for materials should be addressed to V.M.

Reprints and permissions information is available at www.nature.com/reprints.

Publisher's note Springer Nature remains neutral with regard to jurisdictional claims in published maps and institutional affiliations.

\footnotetext{
(c) (i) Open Access This article is licensed under a Creative Commons Attribution 4.0 International License, which permits use, sharing, adaptation, distribution and reproduction in any medium or format, as long as you give appropriate credit to the original author(s) and the source, provide a link to the Creative Commons licence, and indicate if changes were made. The images or other third party material in this article are included in the article's Creative Commons licence, unless indicated otherwise in a credit line to the material. If material is not included in the article's Creative Commons licence and your intended use is not permitted by statutory regulation or exceeds the permitted use, you will need to obtain permission directly from the copyright holder. To view a copy of this licence, visit http://creativecommons.org/licenses/by/4.0/.
}

(C) The Author(s) 2021 